Check for updates

Cite this: RSC Adv., 2019, 9, 27602

Received 9th July 2019

Accepted 28th August 2019

DOI: $10.1039 / c 9 r a 05225 a$

rsc.li/rsc-advances

\section{Study of the pore structure and size effects on the electrochemical capacitor behaviors of porous carbon/quinone derivative hybrids $\uparrow$}

\author{
Hiroyuki Itoi, (D) *a Shuka Tazawa, ${ }^{a}$ Hideyuki Hasegawa, ${ }^{a}$ Yuichiro Tanabe, ${ }^{a}$ \\ Hiroyuki Iwata ${ }^{b}$ and Yoshimi Ohzawa ${ }^{a}$
}

We demonstrate the hybridization of a redox-active quinone derivative, 2,5-dichloro-1,4-benzoquinone (DCBQ), and porous carbons with different pore structures for aqueous electrochemical capacitor electrodes. The hybridization is performed in the gas phase, which enables accurate porous carbon/ DCBQ weight ratios. This method is advantageous over conventional liquid phase adsorption, in terms of facile optimization of the porous carbon/DCBQ weight ratio to obtain high-performance aqueous electrochemical capacitor electrodes, dependent on the kind of porous carbons; moreover, complete adsorption in the liquid phase cannot be achieved by the conventional liquid phase adsorption method. Their electrochemical capacitor performances are evaluated using an aqueous $1 \mathrm{M} \mathrm{H}_{2} \mathrm{SO}_{4}$ electrolyte, and the adsorbed $\mathrm{DCBQ}$ undergoes redox reactions inducing pseudocapacitance within the pores of porous carbons. To study the effect of the pore size on the electrochemical capacitor behavior, two kinds of activated carbon (AC) with different pore sizes are examined: the microporous $A C$ and the AC with both micro- and mesopores. Additionally, we examine ordered microporous carbon with a uniform pore size of $1.2 \mathrm{~nm}$ and a three-dimensionally (3D) ordered and mutually connected pore structure. The results reveal that mesopores facilitate proton conduction inside the $D C B Q$-constrained carbon pores, whereas the 3D-ordered and mutually connected micropores balance high volumetric capacitance enhancement with excellent rate capability. Such high proton conduction inside such constrained spaces can be explained only by the Grotthuss mechanism.

\section{Introduction}

Carbon materials in the forms of graphite, carbon fiber, activated carbon (AC), etc., have widely permeated our society, in households and industry. They have conductive, chemically stable, and strong but light properties, and their structural diversity has facilitated their versatile applications. In addition to conventional carbon materials, nanostructured carbon materials such as fullerene, ${ }^{1}$ carbon nanotubes, ${ }^{2,3}$ and graphene $^{4}$ have been developed by many chemical and physical scientists over the past decades. These nanostructured carbon materials are characterized by multiple-dimensional ordered structures; therefore, their structural accuracy has facilitated the development of computational science and nanostructured devices based on their theoretical and experimental results. ${ }^{5-7}$

${ }^{a}$ Department of Applied Chemistry, Aichi Institute of Technology, Yachigusa 1247, Yakusa-cho, Toyota, 470-0392, Japan.E-mail: itoi-hiroyuki@aitech.ac.jp

${ }^{b}$ Department of Electrical and Electronics Engineering, Aichi Institute of Technology, Yachigusa 1247, Yakusa-cho, Toyota, 470-0392, Japan

$\dagger$ Electronic supplementary information (ESI) available. See DOI: 10.1039/c9ra05225a
The advances in these nanostructured carbon materials have facilitated the emergence of versatile nanostructured carbon materials, and theoretical and analytical studies have been further developed for adapting new materials. The development of nanostructured carbon materials by many researchers is ongoing; the hybridization of conventional carbon materials with appropriate compounds could also afford additional and unexpected properties. ${ }^{8-11}$ Among conventional carbon materials, AC has the greatest potential due to its low-cost, large surface area, high electrical conductivity, and strong adsorption capability. With these properties, AC functions as a host material and hybridizes with numerous organic and inorganic guest materials. Recently, we reported the hybridization of AC with conductive polymers ${ }^{12,13}$ and redox-active organic compounds, ${ }^{\mathbf{1 4 , 1 5}}$ whereby they were introduced inside the AC pores. Consequently, through the hybridization, a large contact area between the guest materials and conductive carbon surface with high dispersity was achieved. Redox-active organic compounds and even conductive polymers have poor electrical conductivity in comparison with those of carbon materials; however, with this hybridization method, the rapid charge transfer at the interface could be achieved, i.e., the guest materials are, in appearance, furnished with electrical 
conductivity. Moreover, this hybridization can be applied to not only AC but also to other porous carbons. The rapid charge transfer characteristics are advantageous for electrode materials with high power densities, and the hybrid materials exhibit superior performance as electrochemical capacitor electrodes compared to the case with nanostructured carbons. Organic and inorganic materials have diverse properties, and their hybridization with porous carbons is expected to result in synergetic effects for various devices and applications. ${ }^{\mathbf{1 6 , 1 7}}$ Although the properties of AC and other porous carbons have mainly been characterized by their pore structures and sizes, their effects on the performance of porous carbon/guest material hybrids in devices have not been studied in detail.

Here, we investigate the electrochemical capacitor behaviors of the hybrids of a redox-active organic compound, 2,5-dichloro-1,4-benzoquinone (DCBQ), with a variety of porous carbons: microporous AC, AC with micro- and mesopores, and ordered microporous carbon. DCBQ is a quinone derivative and hydrophobic due to the present chlorine atoms. Once DCBQ is adsorbed in porous carbons, the porous carbon/DCBQ hybrids can be used as electrodes in aqueous electrochemical capacitors through the DCBQderived pseudocapacitance without dissolution of DCBQ in the electrolyte solution. ${ }^{14}$ DCBQ is adsorbed in the gas phase with accurate porous carbon/DCBQ weight ratios, which is impossible for the conventional liquid phase adsorption method due to the concomitant solvent molecule adsorption and the impossibility of complete adsorption of the adsorbate in the liquid phase. With the ability to accurately control the weight ratios, the optimization of the porous carbon/ DCBQ weight ratio for the high-performance electrodes in electrochemical capacitors can be facilitated, depending on the kind of porous carbons, because the weight ratio mainly determines the performance of the resulting hybrids in electrochemical capacitors. ${ }^{15}$ This method enables fine dispersion of DCBQ in the pores of porous carbons and does not require organic solvents, concomitant solvent removal, and purification process (i.e., so-called solvent-free preparation). Counterions play an important role in redox reactions since most redox-active materials are charged during the redox reaction. ${ }^{15,18,19}$ In contrast, quinone derivatives maintain electroneutrality by protonation in proton acidic electrolytes during the redox reaction, thereby becoming hydroquinone derivatives. The size of DCBQ is $\sim 0.5 \mathrm{~nm}$, which is equivalent to the size of the micropore; however, the adsorbed DCBQ can undergo a rapid redox reaction within such constrained pore spaces. There are two possible mechanisms of proton conduction within such constrained pore spaces: Grotthuss ${ }^{20,21}$ and vehicle mechanisms. ${ }^{22}$ These mechanisms often compete when applied together in cases that cannot be explained only by one mechanism. The correlation between the pore structures, pore sizes, and the electrochemical capacitor performances of the porous carbon/DCBQ hybrids are systematically discussed. Based on the experimental results obtained in this study, it is concluded that the proton conduction in such constrained spaces can be explained only by the Grotthuss mechanism.

\section{Experimental methods}

\section{Materials}

Two kinds of commercial AC, MSP20N and MSC30 (mAC and mmAC, respectively: Kansai Coke and Chemicals Co., Ltd) and 2,5-dichloro-1,4-benzoquinone (DCBQ: Tokyo Chemical Industry Co., Ltd.) were used as received.

\section{Synthesis}

Zeolite templated carbon was synthesized using NaY zeolite ( $\mathrm{Si}$ / $\mathrm{Al}=5.5$, FUJIFILM Wako Pure Chemical Corp.) as the template, according to the procedure reported elsewhere. ${ }^{23}$ Briefly, a twostep process for filling carbon into the zeolite pores was performed using furfuryl alcohol (FA) and propylene as carbon sources. FA was first adsorbed in the zeolite in the liquid phase, and the adsorbed FA was subjected to polymerization at $150{ }^{\circ} \mathrm{C}$. Subsequently, the chemical vapor deposition (CVD) of propylene was performed to fill the zeolite pores with carbon, followed by heat treatment at $900{ }^{\circ} \mathrm{C}$ for carbonization. Finally, the template zeolite was removed by washing with $\mathrm{HF}$.

Adsorption of DCBQ was performed using a glass ampoule. ${ }^{\mathbf{1 4}}$ Porous carbon was inserted into the ampoule and dried at $150{ }^{\circ} \mathrm{C}$ for $6 \mathrm{~h}$ under vacuum. The amount of dried porous carbon was measured from the weight difference between the empty ampoule and the ampoule containing the dried porous carbon. DCBQ was precisely weighed to achieve an accurate porous carbon/DCBQ weight ratio. The weighed DCBQ was introduced into a small glass tube, and the tube was inserted into the glass ampoule, after which the ampoule was sealed under vacuum and maintained at $100{ }^{\circ} \mathrm{C}$ for $24 \mathrm{~h}$. The completion of the adsorption was confirmed by the disappearance of DCBQ in the glass tube. The hybrid saturated with DCBQ was prepared using an excess amount of DCBQ, and the saturation amount was calculated from the yield and the weight of the dried porous carbon.

\section{Analysis}

$\mathrm{X}$-ray diffraction analysis was performed using an XRD-6100 instrument (Shimadzu) with $\mathrm{Cu} \mathrm{K} \alpha$ radiation $(\lambda=1.5418 \AA)$, at an accelerating voltage of $30 \mathrm{kV}$ and a current of $20 \mathrm{~mA}$. Raman spectra were collected using a Renishaw inVia Raman microscope with a $532 \mathrm{~nm}$ laser line. Nitrogen adsorption/ desorption measurement was conducted with ASAP2020 at $-196^{\circ} \mathrm{C}$. Prior to the analysis, the porous carbons were dried at $150{ }^{\circ} \mathrm{C}$ for $6 \mathrm{~h}$ under vacuum. The porous carbon/DCBQ hybrids were measured without drying to prevent the desorption of DCBQ. The prepared hybrid was introduced into an analysis cell under a nitrogen gas atmosphere. The Brunauer-EmmettTeller specific surface area (BET SSA) was calculated using the adsorption isotherm at $P / P_{0}=0.05-0.20$. The BET SSAs of ZTC and ZTC/DCBQ hybrids were calculated using the adsorption isotherm at $P / P_{0}=0.01-0.05$ to prevent overestimation. ${ }^{23-25}$ The total pore volume $\left(V_{\text {total }}\right)$ was determined from the adsorption amount at $P / P_{0}=0.96$. The micropore volume $\left(V_{\text {micro }}\right)$ was estimated by the Dubinin-Radushkevich method. The mesopore volume $\left(V_{\text {meso }}\right)$ was calculated by subtracting the 
micropore volume from the total pore volume $\left(V_{\text {meso }}=V_{\text {total }}-\right.$ $\left.V_{\text {micro}}\right)$. Transmission electron microscopy (TEM) and energy dispersive X-ray spectroscopy (EDS) analyses were performed with a JEM-2100Plus (JEOL) equipped with a Noran System 7 EDS system integrated with a scanning device comprising bright-field (BF) and annular dark-field (ADF) detectors. The accelerating voltage for TEM imaging was $200 \mathrm{kV}$. Scanning electron microscopy (SEM) analysis was performed with a Superscan SS-550 (Shimadzu) at an accelerating voltage of 15 $\mathrm{kV}$.

\section{Density measurement}

The samples were mixed with binder (polytetrafluoroethylene: PTFE, DuPont) and carbon black (CB: DENKA BLACK Li, Denka Company Ltd.) at a weight ratio of porous carbon (i.e., excluding the DCBQ content), binder, and CB of $18: 1: 1$. The mixture was pressed into a pellet with a diameter of $13 \mathrm{~mm}$ under precisely controlled conditions (30 MPa, $150 \mathrm{~s}$ ) using a Compact Table-Top Universal/Tensile Tester (EZ-LX, Shimadzu). The weight and thickness were precisely measured using a microbalance (XPR2V, Mettler Toledo) and a micrometer (DIGIMICRO, MF-501, Nikon), respectively, from which the density was determined. The theoretical densities $\left(\rho^{\text {theo }}\right)$ were calculated using the experimental densities of the corresponding porous carbons $\left(\rho_{\mathrm{PC}}^{\mathrm{ex}}\right)$ and the weight percent of DCBQ in the hybrids (i.e., $X$ ), assuming that all the DCBQ molecules were completely adsorbed in the porous carbon without expansion of the porous carbon particles, according to the following equation: ${ }^{13}$

$$
\rho^{\text {theo }}=\rho_{\mathrm{PC}}^{\mathrm{ex}}\left(\frac{90}{100-X}+0.1\right)
$$

\section{Electrochemical measurement}

A three-electrode cell was constructed for the electrochemical measurement. All the electrochemical measurements were performed with a potentiostat/galvanostat instrument (VMP3, Bio-logic) at $25^{\circ} \mathrm{C}$. For the working electrode preparation, the sample, PTFE, and CB were mixed in the same manner as described above. The mixture containing $8.5 \mathrm{mg}$ of porous carbon was weighed and formed into a $12 \times 12 \mathrm{~mm}$ sheet, which was sandwiched with stainless steel mesh (100 mesh, Nilaco) under the same condition described above. The counter electrode was prepared from mmAC using the same procedure as that used for the working electrode, except using $20 \mathrm{mg}$ of the mixture. The working and counter electrodes were immersed into an aqueous $1 \mathrm{M} \mathrm{H}_{2} \mathrm{SO}_{4}$ electrolyte solution under vacuum at room temperature for $10 \mathrm{~min}$, and subsequently maintained at $40{ }^{\circ} \mathrm{C}$ for 3 days. $\mathrm{Ag} / \mathrm{AgCl}$ electrode with a saturated aqueous $\mathrm{KCl}$ solution was used as a reference electrode. Cyclic voltammetry (CV) was conducted for four cycles, and the values for the fourth cycle of the $\mathrm{CV}$ were plotted. Impedance analysis was performed with a potential amplitude of $10 \mathrm{mV}$ at the oxidation peak potential and $0.5 \mathrm{~V}$ ( $v s$. $\mathrm{Ag} / \mathrm{AgCl})$ for the porous carbon/ DCBQ hybrids and porous carbons, respectively. The galvanostatic charge/discharge analysis was conducted from $20 \mathrm{~A} \mathrm{~g}^{-1}$ to $50 \mathrm{~mA} \mathrm{~g}^{-1}$. The volumetric current $\left(I_{\mathrm{v}}\right)$ and volumetric capacitance $\left(C_{\mathrm{v}}\right)$ were calculated based on the volume, inclusive of the porous carbon, $\mathrm{DCBQ}, \mathrm{CB}$, and binder, using the following equation:

$$
\begin{gathered}
I_{\mathrm{v}}=I_{\mathrm{g}}\left(\frac{900 \rho^{\mathrm{ex}}}{1000-X}\right) \\
C_{\mathrm{v}}=C_{\mathrm{g}}\left(\frac{900 \rho^{\mathrm{ex}}}{1000-X}\right)
\end{gathered}
$$

where, $\rho^{\text {ex }}$ is the experimental electrode density; $I_{\mathrm{g}}$ and $C_{\mathrm{g}}$, the gravimetric current and the gravimetric capacitance, respectively, calculated based on the mass inclusive of the weights of porous carbon and DCBQ. ${ }^{13}$

\section{Results and discussion}

The pore structures of porous carbons affected the redox characteristics of the redox-active materials adsorbed inside the pores, and two kinds of $\mathrm{KOH}$-activated carbon (AC): one with micropores (mAC) and the other with micro- and mesopores (mmAC), and zeolite-templated carbon (ZTC) were selected as porous carbon substrates. Since the carbon structure of ZTC is developed inside the three-dimensionally (3D) ordered and mutually connected zeolite pores, the ZTC also has a 3D graphene-based network with a uniform pore size of $1.2 \mathrm{~nm} .^{26}$ These three porous carbons were filled with 2,5-dichloro-1,4benzoquinone (DCBQ) in the gas phase. Unlike the conventional liquid phase adsorption method, the gas phase adsorption method enables the precise control of the porous carbon/ DCBQ weight ratio. This method is called the solvent-free preparation method, and it does not require organic solvents, concomitant solvent removal, or purification of obtained materials.

Fig. 1 shows the XRD patterns of the porous carbon/DCBQ hybrids, together with the pristine porous carbons and DCBQ. The hybrids prepared from $\mathrm{mAC}$, mmAC, and ZTC are denoted as mAC/DCBQ $(X), \mathrm{mmAC} / \mathrm{DCBQ}(X)$, and ZTC/DCBQ $(X)$, respectively, where $X$ represents the weight percent of DCBQ in the hybrids. The hybrids, mAC/DCBQ (55.1\%), mmAC/DCBQ (71.2\%), and ZTC/DCBQ (72.3\%) are saturated with DCBQ, which were prepared using an excess amount of DCBQ. As discussed below, the saturation amounts depend on the total pore volumes of the porous carbons. Once the saturation amount is determined, further addition of DCBQ is unnecessary; therefore, this method minimally suppresses environmental burdens. All the pristine porous carbons are characterized by the absence of a carbon (002) diffraction peak because both ACs are highly activated with KOH. Meanwhile, the carbon framework of ZTC is developed only inside the zeolite pores under precisely controlled synthetic conditions, and such constrained zeolite spaces do not allow the stacking of carbon, thus making the ZTC structure a graphene network. ${ }^{24,26}$ In addition, ZTC has a distinct peak at $6.3^{\circ}$, corresponding to the (111) plane of NaY zeolite (Fig. 1c). ${ }^{27}$ The fine dispersion of 
a)

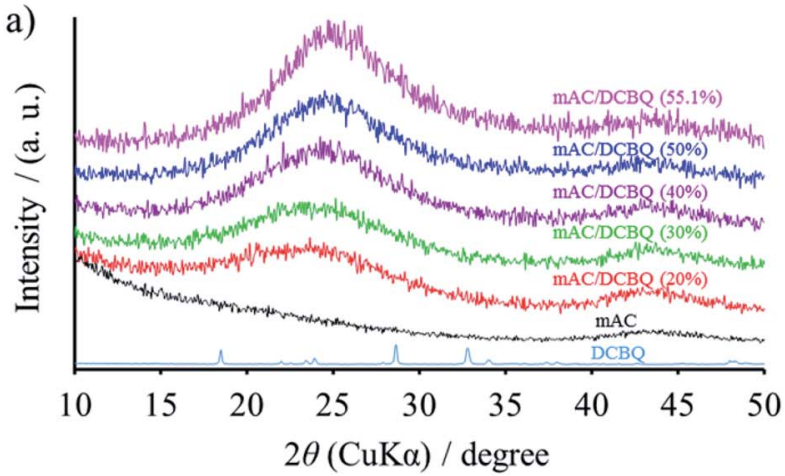

b)

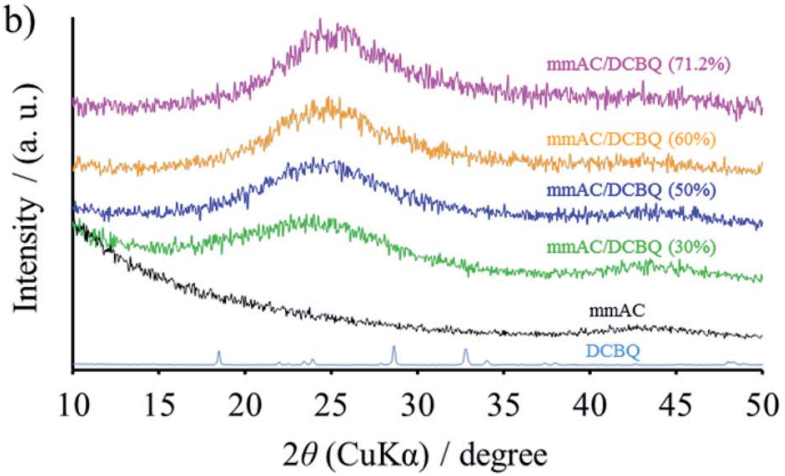

c)
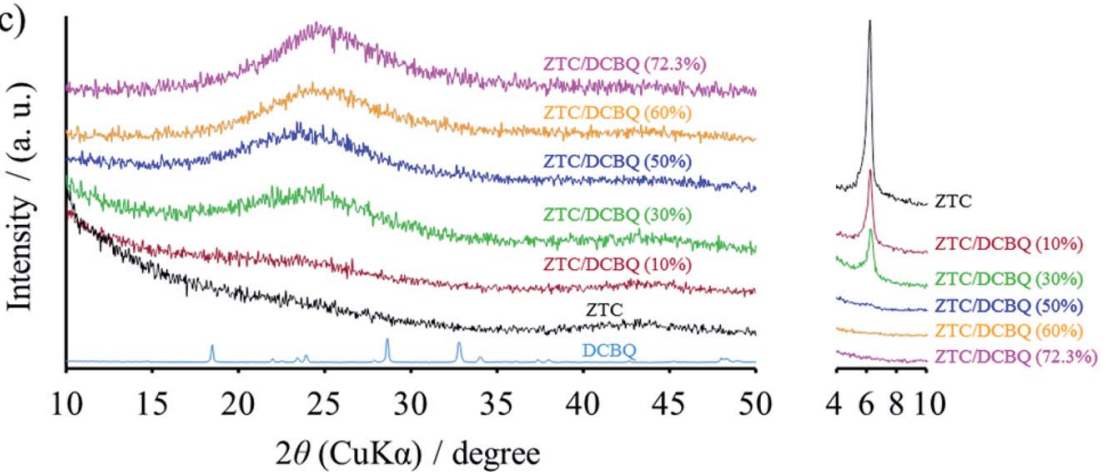

Fig. 1 XRD patterns of (a) $\mathrm{mAC} / \mathrm{DCBQ}$, (b) mmAC/DCBQ, and (c) ZTC/DCBQ hybrids. The XRD patterns of $D C B Q$ and the corresponding porous carbons are plotted together.

DCBQ inside the pores of porous carbons can be confirmed by the absence of the distinct peaks derived from DCBQ crystals. Instead, the intensity of the broad peak at $\sim 25^{\circ}$ increases with increasing DCBQ contents in the hybrids. During gas phase adsorption at the sublimation temperature of DCBQ, the DCBQ molecules were vaporized and adsorbed in the pores of the porous carbons without the deposition of the DCBQ crystals on the particle surface of the porous carbons. The fine dispersion was realized due to the strong adsorption capability of the porous carbons and the relatively high vapor pressure of the redox-active organic compounds. The broad peak in the XRD patterns suggests that the DCBQ molecules were not supported as a single molecule but dispersed as clusters consisting of multiple DCBQ molecules. Since the clusters are restricted within the nanosized constraints, the clusters cannot form a sufficiently crystalline structure ${ }^{16}$ for displaying distinct peaks in their XRD patterns. Moreover, this is supported by the results of their electrochemical behavior (vide infra). The distinct peak of ZTC indicates the trend of decreasing intensity with increasing DCBQ content, and the patterns of the ZTC/DCBQ hybrids with DCBQ content of more than $50 \mathrm{wt} \%$ no longer show the distinct peak (Fig. 1c). The absence of the distinct peak in the XRD patterns does not indicate any structural collapse of ZTC by the adsorption of DCBQ molecules.

Raman spectroscopy analysis can confirm that there is no change in the graphene-based network structure of ZTC upon the adsorption of DCBQ. Fig. 2 shows the Raman spectra of ZTC, ZTC/DCBQ (30\%), and ZTC/DCBQ (60\%), and they exhibit almost the same spectra with the same ratio of $\mathrm{D}$ and $\mathrm{G}$ band intensities, indicating that the graphene-based network structure of ZTC is retained after the adsorption of DCBQ. The graphene-based framework of ZTC is curved and does not have any stack of graphenes; ${ }^{26}$ such structural morphology affords ZTC with an elastic property. We have reported the reversible pore size control of ZTC by mechanical pressure without the structural collapse of the ZTC framework. ${ }^{28}$ As discussed below, the ZTC frameworks of ZTC/DCBQ (50\%) and ZTC/DCBQ (60\%) were contracted by the adsorbed DCBQ molecules; however, the

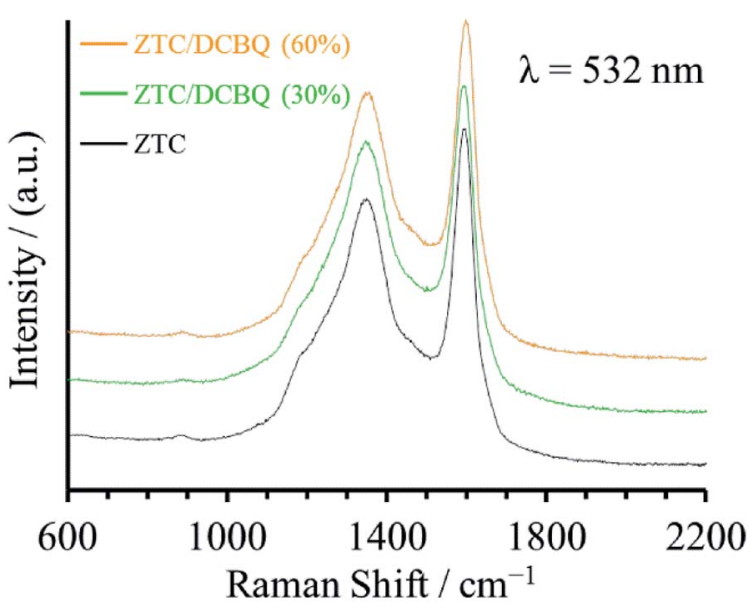

Fig. 2 Raman spectra of ZTC, ZTC/DCBQ (30\%), and ZTC/DCBQ (60\%). 
Raman spectra show that the adsorption of DCBQ in ZTC is not accompanied by any structural collapse of the ZTC framework.

The nitrogen adsorption and desorption measurement revealed decreasing surface areas and pore volumes of the hybrids with increasing DCBQ content (Fig. 3 and Table 1). Fig. 3a-c show the nitrogen adsorption/desorption isotherms of the $\mathrm{mAC} / \mathrm{DCBQ}$, mmAC/DCBQ, and ZTC/DCBQ hybrids, respectively, together with that of the pristine porous carbons. In addition, the pore size distributions (PSDs) of the corresponding samples are plotted in Fig. 3d-f. The nitrogen adsorption/desorption isotherms of the pristine porous carbons show steep uptake derived from micropore filling in the low relative pressure region below $P / P_{0} \approx 0.1$. In addition, mmAC shows moderate nitrogen adsorption up to $P / P_{0} \approx 0.3$ (Fig. 3b), indicating that mmAC possesses both micro- and mesopores. The mAC/DCBQ and ZTC/DCBQ hybrids show decreasing micropore filling with increasing DCBQ content (Fig. 3a and c), and consequently, their surface areas and micropore volumes decrease with increasing DCBQ content (Table 1, Fig. 3d and f). For the mmAC/DCBQ hybrids, both micro- and mesopores were filled with adsorbed DCBQ, irrespective of the DCBQ content, which is clearly confirmed by their adsorption/desorption isotherms and PSDs (Fig. 3b and e). Recently, we reported a similar concerted micro- and mesopore filling process of porous carbon black, which had both micro- and mesopores $(<c a .20 \mathrm{~nm}) .{ }^{14}$ The hybrids saturated with DCBQ no longer have any surface area and pore volume, and the saturation amounts of DCBQ per unit mass of the porous carbons are in proportional to their total pore volumes (Fig. S1 $\dagger$ ). However, the decrease in the surface area by the same adsorption amount of DCBQ differs depending on the kind of the porous carbons. For example, ZTC has a larger surface area than mmAC; however, the ZTC/DCBQ hybrids exhibit a larger decrease in the surface area compared to the case with the mmAC/DCBQ hybrids at the same adsorption amount. This result suggests that the ZTC/ DCBQ hybrids should have pores with sizes less than that of a $\mathrm{N}_{2}$ molecule, which is the probe gas of the gas adsorption/ desorption measurement performed in this study. The difference in the pore structures and sizes geometrically affects the molecular packing inside the pores. These small pores play an important role in the redox reaction of DCBQ, depending on the kind of pore structures (vide infra).

The morphologies of the porous carbon/DCBQ hybrids were confirmed by scanning electron microscopy (SEM). Fig. $4 \mathrm{a}-\mathrm{f}$ show the SEM images of the pristine porous carbons and the hybrids saturated with DCBQ. As was indicated by the results of the XRD analysis, even the hybrids saturated with DCBQ did not change in the morphology compared to those of the pristine porous carbons because DCBQ exists inside the pores of porous carbon particles. The hybrids also could not be differentiated from the pristine porous carbons by transmission electron microscopy (TEM) because DCBQ consists of light elements and exists inside the AC particles. ${ }^{\mathbf{1 4}}$ Fig. $4 \mathrm{~g}-\mathrm{j}$ show the TEM images of mmAC and mmAC/DCBQ (60\%). Although the mass of DCBQ in $\mathrm{mmAC} / \mathrm{DCBQ}(60 \%)$ per gram of $\mathrm{AC}$ is as much as $1.5 \mathrm{~g}$, there is no difference in their TEM images. However, energy dispersive X-ray spectroscopy (EDS) analysis revealed the dispersion of DCBQ molecules over the whole porous carbon particles (Fig. 4k). Previously, we demonstrated the density measurement of porous carbon/ organic compound hybrids. ${ }^{15}$ In addition to the results of the $\mathrm{XRD}$ analysis, the comparison between the experimental and theoretical electrode densities further confirms that there are negligible adsorbate molecules on the particle surface of the
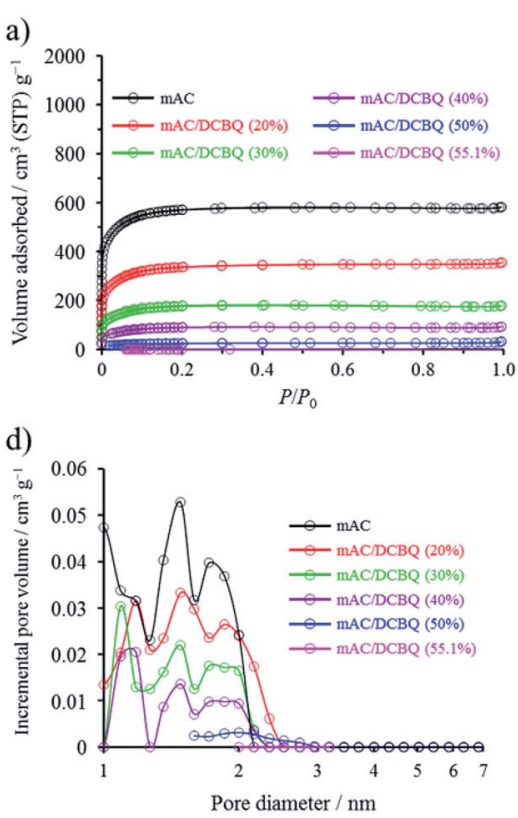

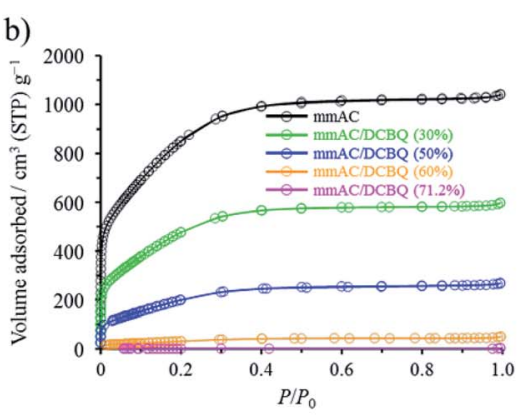

e)

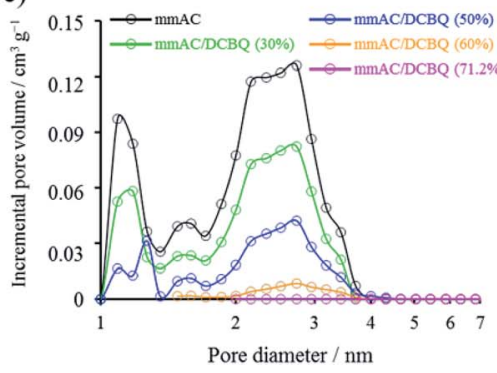

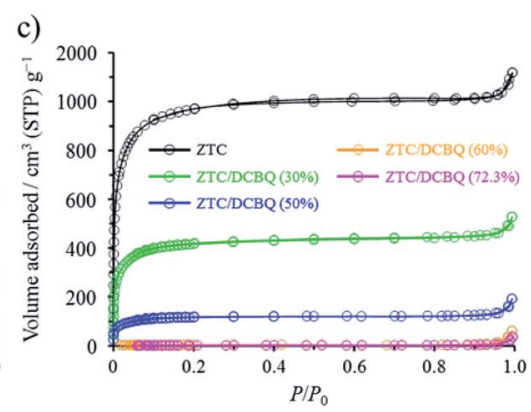

f)

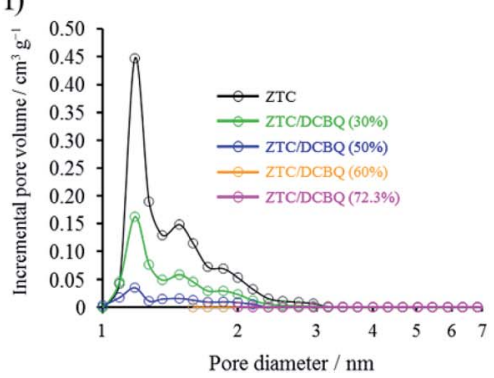

Fig. 3 Results of nitrogen adsorption/desorption measurements for porous carbon/DCBQ hybrids. (a-c) Nitrogen adsorption/desorption isotherms for (a) $\mathrm{mAC} / D C B Q$, (b) $\mathrm{mmAC} / \mathrm{DCBQ}$, and (c) ZTC/DCBQ hybrids. (d-f) PSDs for (d) $\mathrm{mAC/DCBQ}$, (e) $\mathrm{mmAC/DCBQ}$, and (f) ZTC/DCBQ hybrids. The results of the corresponding porous carbons are plotted together. 
Table 1 BET SSAs and pore volumes of porous carbon/DCBQ hybrids, shown alongside the corresponding porous carbons

\begin{tabular}{|c|c|c|c|c|c|c|c|c|c|c|c|c|}
\hline \multirow[b]{2}{*}{$\begin{array}{l}\text { DCBQ } \\
\text { (wt\%) }\end{array}$} & \multicolumn{4}{|l|}{$\mathrm{mAC}$} & \multicolumn{4}{|l|}{ mmAC } & \multicolumn{4}{|l|}{ ZTC } \\
\hline & $\begin{array}{l}S_{\mathrm{BET}}^{a} \\
\left(\mathrm{~m}^{2} \mathrm{~g}^{-1}\right)\end{array}$ & $\begin{array}{l}V_{\text {total }}^{b} \\
\left(\mathrm{~cm}^{3} \mathrm{~g}^{-1}\right)\end{array}$ & $\begin{array}{l}V_{\text {micro }}{ }^{2} \\
\left(\mathrm{~cm}^{3} \mathrm{~g}^{-1}\right)\end{array}$ & $\begin{array}{l}V_{\text {meso }}{ }^{d} \\
\left(\mathrm{~cm}^{3} \mathrm{~g}^{-1}\right)\end{array}$ & $\begin{array}{l}S_{\mathrm{BET}}^{a} \\
\left(\mathrm{~m}^{2} \mathrm{~g}^{-1}\right)\end{array}$ & $\begin{array}{l}V_{\text {total }}^{b} \\
\left(\mathrm{~cm}^{3} \mathrm{~g}^{-1}\right)\end{array}$ & $\begin{array}{l}V_{\text {micro }}{ }^{-1} \\
\left(\mathrm{~cm}^{3} \mathrm{~g}^{-1}\right)\end{array}$ & $\begin{array}{l}V_{\text {meso }}{ }^{d} \\
\left(\mathrm{~cm}^{3} \mathrm{~g}^{-1}\right)\end{array}$ & $\begin{array}{l}S_{\mathrm{BET}}{ }^{a} \\
\left(\mathrm{~m}^{2} \mathrm{~g}^{-1}\right)\end{array}$ & $\begin{array}{l}V_{\text {total }} b \\
\left(\mathrm{~cm}^{3} \mathrm{~g}^{-1}\right)\end{array}$ & $\begin{array}{l}V_{\text {micro }}{ }^{c} \\
\left(\mathrm{~cm}^{3} \mathrm{~g}^{-1}\right)\end{array}$ & $\begin{array}{l}V_{\text {meso }}{ }^{d} \\
\left(\mathrm{~cm}^{3} \mathrm{~g}^{-1}\right)\end{array}$ \\
\hline $0^{e}$ & 1980 & 0.89 & 0.84 & 0.05 & 3160 & 1.59 & 0.99 & 0.60 & 3730 & 1.68 & 1.57 & 0.11 \\
\hline \multicolumn{13}{|l|}{10} \\
\hline 20 & 1170 & 0.54 & 0.49 & 0.05 & & & & & & & & \\
\hline 30 & 620 & 0.27 & 0.25 & 0.02 & 1800 & 0.91 & 0.54 & 0.37 & 1620 & 0.71 & 0.68 & 0.03 \\
\hline 40 & 320 & 0.14 & 0.13 & 0.01 & & & & & & & & \\
\hline 50 & 89 & 0.04 & 0.04 & 0.00 & 760 & 0.40 & 0.22 & 0.18 & 440 & 0.21 & 0.18 & 0.02 \\
\hline 60 & & & & & 120 & 0.07 & 0.04 & 0.03 & 14 & 0.01 & 0.01 & 0.00 \\
\hline Sat. ${ }^{f}$ & $\sim 0$ & - & - & - & $\sim 0$ & - & - & - & $\sim 0$ & - & - & - \\
\hline
\end{tabular}

${ }^{a}$ BET SSAs. ${ }^{b}$ Total pore volumes estimated from the adsorbed nitrogen amount at $P / P_{0}=0.96 .{ }^{c}$ Micropore volumes calculated using the DR method. ${ }^{d}$ Mesopore volumes calculated from $V_{\text {meso }}=V_{\text {total }}-V_{\text {micro. }}{ }^{e}$ The BET SSAs and pore volumes in the line are the values of the corresponding pristine porous carbons. ${ }^{f}$ Saturation value: $55.1,71.2$, and $72.3 \mathrm{wt} \%$ for $\mathrm{mAC}$, mmAC, and ZTC, respectively.
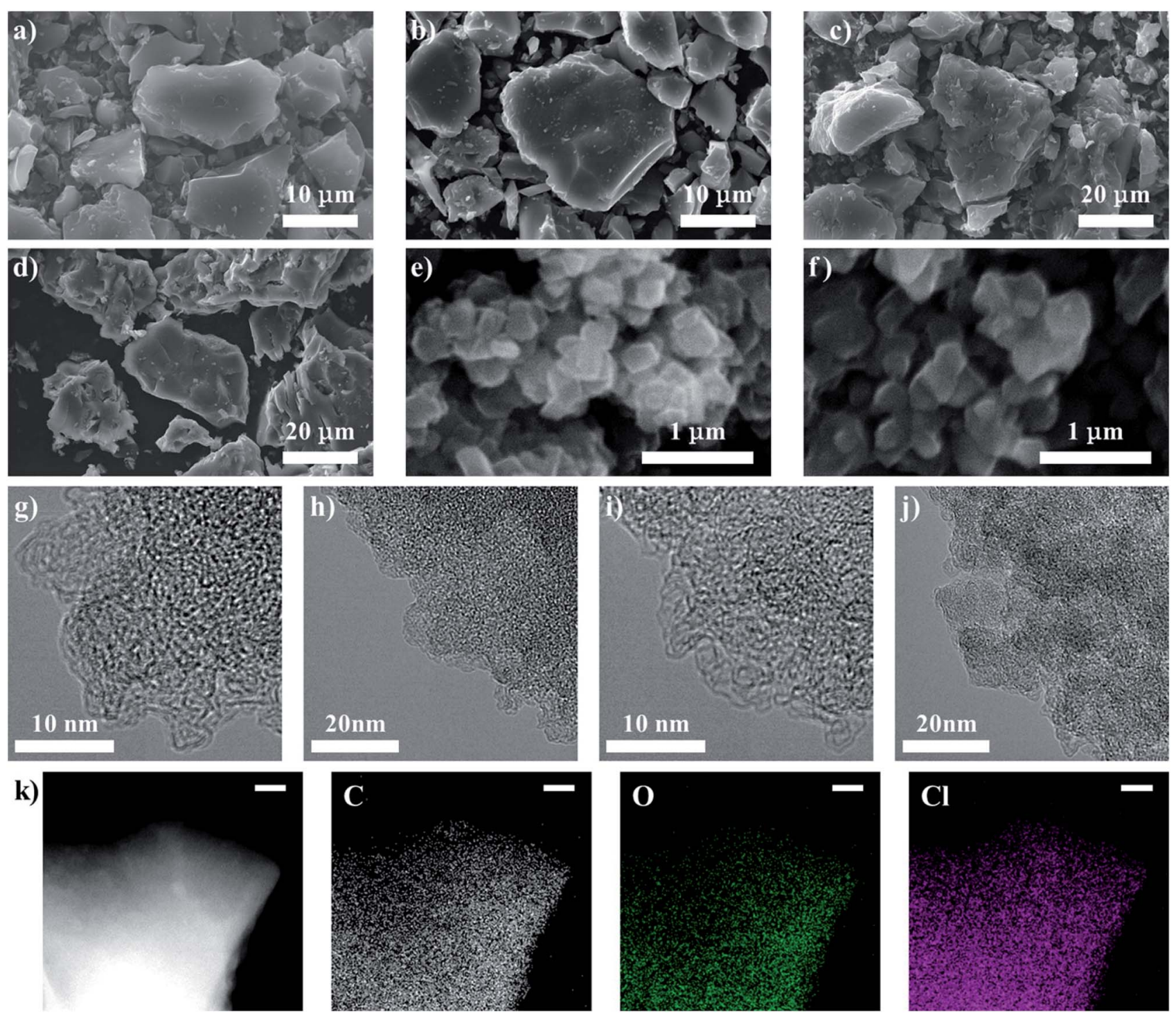

Fig. 4 Morphologies of the pristine porous carbons and porous carbon/DCBQ hybrids. (a-f) SEM images of (a) $m A C$, (b) $m A C / D C B Q(55.1 \%)$, (c) $m m A C$, (d) mmAC/DCBQ (71.2\%), (e) ZTC, and (f) ZTC/DCBQ (72.3\%). (g-j) TEM images of ( $\mathrm{g}$ and $\mathrm{h}$ ) $\mathrm{mmAC}$ and (i and j) $\mathrm{mmAC} / \mathrm{DCBQ}(60 \%)$. (k) STEM image and EDS spectra of $\mathrm{mmAC/DCBQ}(60 \%)$. All the scale bars in panel $(\mathrm{k})$ are $200 \mathrm{~nm}$. 
porous carbons. For the electrochemical measurement, electrodes are prepared by mixing them with the binder and carbon black (CB), followed by pressing using stainless steel mesh under precisely controlled conditions. Similarly, the mixture of the sample, binder, and CB is pressed into a pellet under the same condition to measure the electrode densities (for details, see the Experimental section). The theoretical electrode densities can be calculated using the experimental electrode densities of the pristine porous carbons, based on the assumption that all the adsorbate molecules are completely adsorbed in the pores of the porous carbons. ${ }^{13}$ The experimental and theoretical electrode densities are summarized in Table 2. If the DCBQ molecules are stacked on the particle surface of the porous carbons without adsorption, the experimental electrode densities should be lower than the theoretical values due to the expansion of the electrode. For the $\mathrm{mAC} / \mathrm{DCBQ}$ and mmAC/DCBQ hybrids, the experimental electrode densities of the samples are nearly equal to or slightly higher than the theoretical values with differences below $6 \%$. This result confirms that there is a negligible amount of the DCBQ molecules on the particle surface of the porous carbons. Meanwhile, the experimental electrode densities of the ZTC/DCBQ hybrids are in good agreement with the theoretical values with the exception of those of ZTC/DCBQ (50\%) and ZTC/DCBQ (60\%), which show higher experimental electrode densities with differences of $\sim 13 \%$. Their relatively high electrode densities are probably explained by the elastic properties of ZTC (vide supra), ${ }^{28}$ i.e., the ZTC particles contracted upon the adsorption of DCBQ. The adsorption-induced deformation (contraction and swelling) of the porous materials has been experimentally and theoretically demonstrated for zeolite, AC, and other porous carbons. ${ }^{29-33}$ Despite using the same porous material, contraction and swelling are observed depending on the temperature, the amount of adsorption, and the kind of adsorbates. A detailed study of the adsorption-induced deformation of the ZTC particles is out of the scope of this study. However, it is not strange that the reversible pore size control characteristic of ZTC leads to the adsorption-induced contraction of the ZTC particles without any collapse of the graphene-based framework of ZTC, as shown in the Raman spectra of ZTC and the ZTC/DCBQ hybrids (Fig. 2).
Fig. 5 shows the schematic of the electrodes prepared from the pristine porous carbon (Fig. 5a) and the porous carbon/ DCBQ hybrids (Fig. 5b-d) by mixing with the binder and CB at a weight ratio of porous carbon (i.e., excluding the DCBQ content), binder, and CB of $18: 1: 1$. The figures of the porous carbon/DCBQ hybrids are based on the assumption that all DCBQ molecules are completely adsorbed in the porous carbon without change in the electrode volume. The density of the electrode proportionally increases with the mass of the DCBQ per unit volume of the electrode or per unit mass of the porous carbon because the number and the mass of the porous carbon particles per unit volume are constant, i.e., the correlation coefficient of the mass of DCBQ per unit volume of the electrode is the same as that per unit mass of the porous carbon. Note that the weight percent of DCBQ in the hybrid has a different importance from that of the mass of DCBQ per unit volume of the electrodes, depending on whether the gravimetric or volumetric capacitance is discussed. For example, the mass of DCBQ per $1 \mathrm{~g}$ of the porous carbon is $0.25,1.0$, and $1.5 \mathrm{~g}$ for $\mathrm{mmAC} /$ DCBQ (20\%), mmAC/DCBQ (50\%), and mmAC/DCBQ (60\%), respectively (Fig. 5b-d). Therefore, if their volumetric capacitances proportionally increase with the mass of DCBQ per unit volume of the electrode, the ratio of their volumetric capacitance enhancement would be $1: 4: 6$; however, the total capacitance depends on the sum of the DCBQ-derived pseudocapacitance and the electric double-layer capacitance. In terms of the practical use of energy storage devices, the volumetric capacitance is more important than the gravimetric one, and the above theory helps to discuss the effect of the DCBQ content in the hybrids on the volumetric capacitance enhancement.

All electrochemical measurements were performed at $25{ }^{\circ} \mathrm{C}$ using an aqueous $1 \mathrm{M} \mathrm{H}_{2} \mathrm{SO}_{4}$ electrolyte in a potential range of -0.1 to $0.8 \mathrm{~V}$ ( $v s$. $\mathrm{Ag} / \mathrm{AgCl})$. Fig. 6 summarizes the results of cyclic voltammetry (CV) and galvanostatic charge/discharge (GC) measurements. Note that the current in Fig. 6a-c and the capacitance in Fig. $6 \mathrm{~g}-\mathrm{i}$ are plotted as the values per unit electrode volume inclusive of $\mathrm{CB}$ and binder (i.e., volumetric current $\left(I_{\mathrm{v}}\right)$ and volumetric capacitance $\left.\left(C_{\mathrm{v}}\right)\right)$, which were calculated using the experimental electrode densities (for details, see the Experimental section). ${ }^{13} I_{\mathrm{v}}$ and $C_{\mathrm{v}}$ show the different tendencies from those per unit mass of the active materials (i.e., gravimetric current $\left(I_{\mathrm{g}}\right)$ and gravimetric

Table 2 Experimental and theoretical electrode densities of the samples

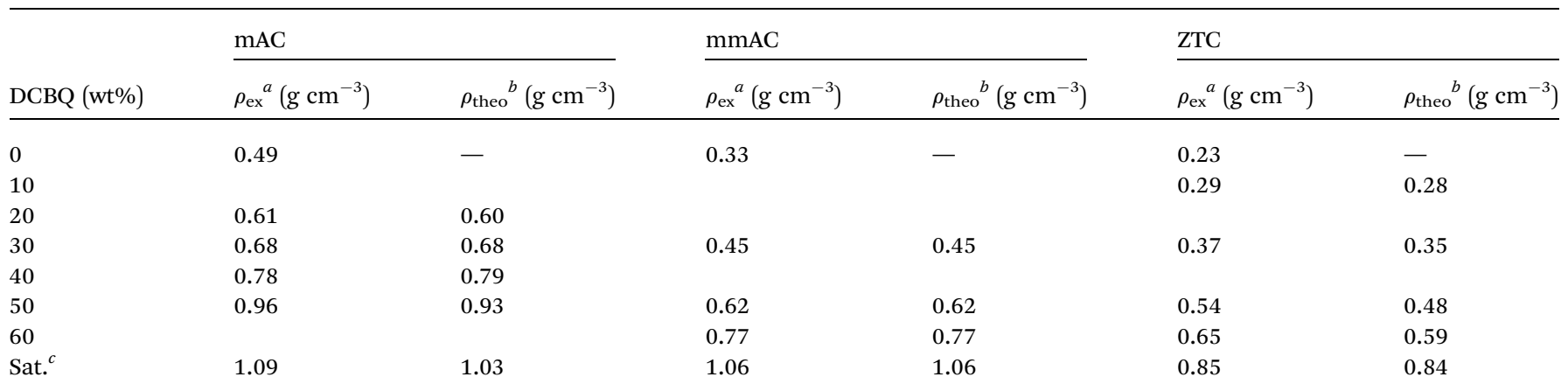

${ }^{a}$ Experimental electrode density. ${ }^{b}$ Theoretical electrode density $\left(\rho_{\text {theo }}=\rho_{\mathrm{PC}}^{\mathrm{ex}}(90 /(100-X)+0.1)\right) .{ }^{c}$ Saturation value: $55.1,71.2$, and 72.3 wt $\%$ for $\mathrm{mAC}$, mmAC, and ZTC, respectively. 
(a)

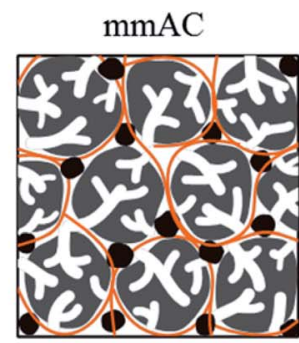

mmAC $: 1 \mathrm{~g}$ (b)

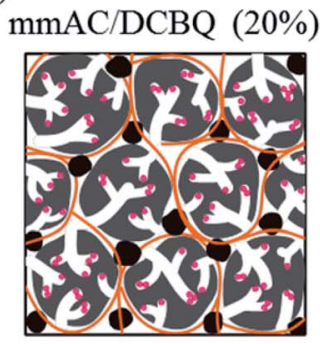

mmAC $: 1 \mathrm{~g}$ $\left(\mathrm{CB}: \frac{1}{18} \mathrm{~g} \bullet\right.$ binder $\left.: \frac{1}{18} \mathrm{~g} \backslash\right)$

DCBQ : $0.25 \mathrm{~g}$

(c)

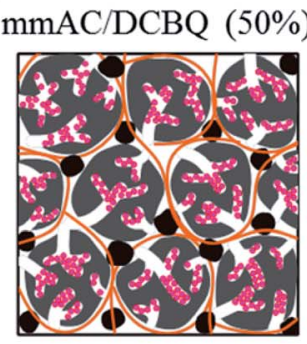

mmAC $: 1 \mathrm{~g}$

DCBQ : $1 \mathrm{~g}$ (d)

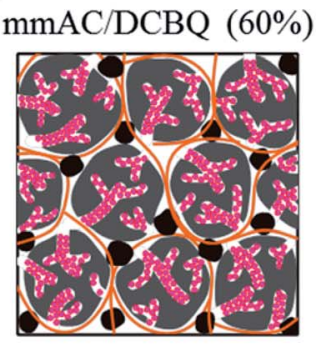

mmAC $: 1 \mathrm{~g}$

DCBQ : $1.5 \mathrm{~g}$

Fig. 5 Schematic of the electrodes of (a) mmAC, (b) mmAC/DCBQ (20\%), (c) mmAC/DCBQ (50\%), and (d) $\mathrm{mmAC/DCBQ} \mathrm{(60 \% ).} \mathrm{The} \mathrm{volumes} \mathrm{of}$ all the electrodes in $(a-d)$ are the same, irrespective of the amount of $D C B Q$ in the samples.
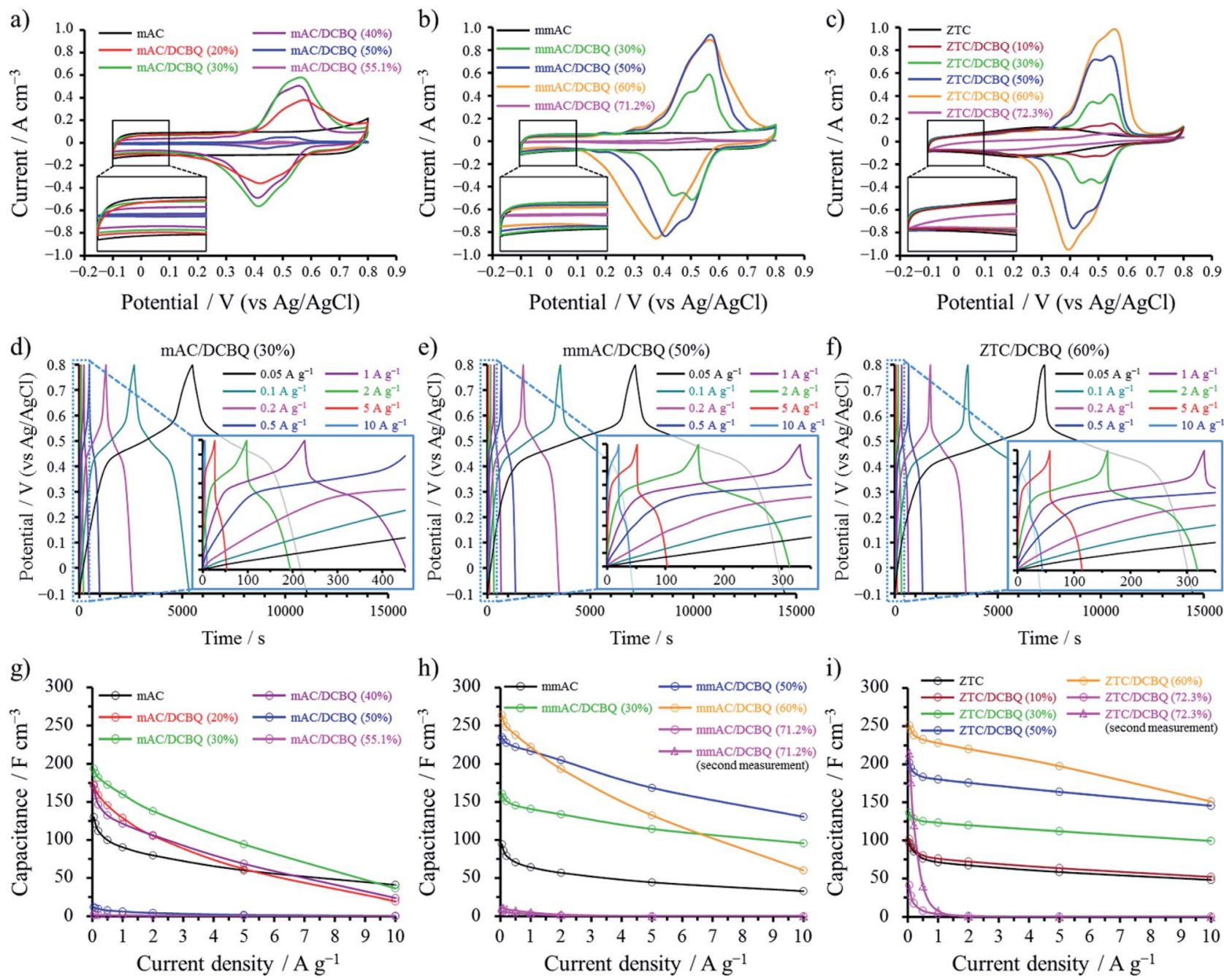

Fig. 6 Results of electrochemical behaviors of porous carbon/DCBQ hybrids and pristine porous carbons. (a-c) Cyclic voltammograms of (a) $\mathrm{mAC} / \mathrm{DCBQ}$, (b) $\mathrm{mmAC} / \mathrm{DCBQ}$, and (c) ZTC/DCBQ hybrids, measured at a sweep rate of $1 \mathrm{mV} \mathrm{s}^{-1}$. The 4th cycle is plotted for each sample. (d-f) Charge/discharge curves of (d) $\mathrm{mAC} / \mathrm{DCBQ}(30 \%)$, (e) $\mathrm{mmAC/DCBQ} \mathrm{(50 \% ),} \mathrm{and} \mathrm{(f)} \mathrm{ZTC/DCBQ} \mathrm{(60 \% ).} \mathrm{(g-i)} \mathrm{Dependence} \mathrm{of} \mathrm{the} \mathrm{volumetric}$ capacitances on the current densities for (g) $\mathrm{mAC} / D C B Q$, (h) $\mathrm{mmAC} / D C B Q$, and (i) ZTC/DCBQ hybrids. All measurements were performed in a potential range of -0.1 to $0.8 \mathrm{~V}$. The currents and capacitances are the values per the electrode volume inclusive of porous carbon, $\mathrm{DCBQ}, \mathrm{CB}$, and binder. The second measurements of mmAC/DCBQ (71.2\%) and mmAC/DCBQ (72.3\%) in (h and i) were performed a week after the first measurement. 
capacitance $\left.\left(C_{\mathrm{g}}\right)\right)$, depending on the weight percent of DCBQ in the hybrids (Fig. S2 $\dagger$ ). The voltammograms of the porous carbon/DCBQ hybrids are characterized by a reversible distinct peak couple. The reversible peak is attributed to the reversible redox reaction of DCBQ occurring within the pores of the porous carbons. In contrast, the pristine DCBQ does not show any redox characteristics due to its insoluble nature in aqueous electrolytes and poor electrical conductivity (Fig. S3†), which validates the present hybridization method using porous carbons. The area of the voltammograms in Fig. 6a-c proportionally correlates to the volumetric capacitance, and many porous carbon/DCBQ hybrids clearly show the volumetric capacitance enhancement by the DCBQ-derived pseudocapacitance. However, some hybrids have detrimental effects on the volumetric capacitance enhancement by DCBQ adsorption, particularly for the hybrids saturated with DCBQ. The optimization of the capacitances by the DCBQ content depends on the kind of porous carbons and can be affected by their pore structures, sizes, and volumes. The pore volume of the porous carbon correlates with the saturation amount (vide supra) and is clearly related to the volumetric capacitance enhancement (Fig. $6 \mathrm{~g}-\mathrm{i}$ ). The pore size effect on the electrochemical behavior of the hybrids can be discussed by comparing the results of the $\mathrm{mAC} / \mathrm{DCBQ}$ and mmAC/DCBQ hybrids (vide infra). The voltammograms of mAC and mmAC show a constant current (i.e., a rectangular shape), typical of electric double-layer behavior (Fig. 6a and b). The current between -0.05 and $0.1 \mathrm{~V}$ observed for the $\mathrm{mAC} / \mathrm{DCBQ}$ and $\mathrm{mmAC} / \mathrm{DCBQ}$ hybrids are constant, and therefore, can be attributed to the double-layer-derived current. The constant current decreases with increasing DCBQ content (Fig. 6a and b, inset), because the adsorbed DCBQ molecules hamper the electric double-layer formation within the AC pores. On the other hand, the current between 0.1 and $0.8 \mathrm{~V}$ is the sum of the electric double-layer- and DCBQ-derived currents. Both currents can be resolved into individual currents (Fig. S4a $\dagger$ ), because the electric double-layer current of mAC and mmAC is basically constant over the whole potential range (Fig. 6a and b). We have reported that not all the DCBQ molecules adsorbed in the porous carbons contribute to the pseudocapacitance, ${ }^{\mathbf{1 4}}$ probably due to the formation of the clusters, as discussed above. The utilization ratios of DCBQ in the porous carbon/ DCBQ hybrids should be affected by the pore structure and the pore size of the porous carbons, in addition to the remaining pore volume of the porous carbon/DCBQ hybrids. The utilization ratio was calculated from the weight percent of DCBQ in the hybrids by integrating the DCBQ-derived current (Fig. S4 $\dagger$ ). This estimation can be enabled by accurate porous carbon/DCBQ weight ratios achieved via solvent-free preparation. Table 3 summarizes the utilization ratios of DCBQ in the hybrids. A clear distinction in the results between the $\mathrm{mAC} /$ DCBQ and mmAC/DCBQ hybrids is that the utilization ratio of DCBQ for the mAC/DCBQ hybrids decreases with relatively small DCBQ contents. This is explained by the mesopore effect on the proton conduction (vide infra).

Unlike the case with the pristine $\mathrm{mAC}$ and $\mathrm{mmAC}$, the pristine ZTC shows a broad redox peak in its voltammogram (Fig. 6c and S2c $\dagger$ ). Since ZTC is subjected to electrochemical
Table 3 Utilization ratios of DCBQ in porous carbon/DCBQ hybrids ${ }^{a}$

\begin{tabular}{lclc}
\hline $\operatorname{DCBQ}(w t \%)$ & $\mathrm{mAC}$ & $\mathrm{mmAC}$ & ZTC \\
\hline 10 & & & 47 \\
20 & 39 & & \\
30 & 41 & 50 & 44 \\
40 & 27 & & \\
50 & 2 & 44 & 40 \\
60 & & 34 & 40 \\
Sat. $^{b}$ & - & $\sim 1$ & $\sim 1$
\end{tabular}

${ }^{a}$ Calculated from the voltammograms measured at $1 \mathrm{mV} \mathrm{s}^{-1}$ in $1 \mathrm{M}$ $\mathrm{H}_{2} \mathrm{SO}_{4}$ considering the two electron redox reaction per one DCBQ molecule. ${ }^{b}$ Saturation value: 55.1, 71.2, and $72.3 \mathrm{wt} \%$ for $\mathrm{mAC}$, $\mathrm{mmAC}$, and ZTC, respectively.

oxidation due to its nanosized graphene structure, a large number of quinone groups are introduced in the edge sites of the pristine ZTC during the 1 st $\mathrm{CV}$ cycle (Fig. S5a $\dagger$ ). ${ }^{34}$ The current in the voltammograms of the ZTC/DCBQ hybrids is the sum of the DCBQ- and quinone-derived currents, together with the electric double-layer current. However, the current derived from the quinone groups decreases with increasing DCBQ content (Fig. 6c and S2c $\dagger$ ), because the electrochemical oxidation of ZTC is suppressed by adsorbed DCBQ, which is strongly supported by the decrease in the oxidation current at the 1st cycle for the ZTC/DCBQ hybrids (Fig. S5b †). This is probably due to the lower charge transfer resistance of the DCBQ adsorbed inside the $\mathrm{AC}$ pores compared to the oxidation resistance of ZTC. The results of the impedance analysis support this idea with the fact that the charge transfer resistances of the ZTC/ DCBQ hybrids are not so high in comparison with that of ZTC, despite the substantial contribution from DCBQ-derived pseudocapacitance (Fig. S6†). Instead of the decrease in the quinone-derived current, the DCBQ-derived current increases with the DCBQ contents, except for ZTC/DCBQ (72.3\%). Although the surface area of $\mathrm{mAC} / \mathrm{DCBQ}(50 \%)$ is comparable to that of mmAC/DCBQ $(60 \%)$ and larger than that of ZTC/DCBQ $(60 \%)$, the utilization ratio of DCBQ for mAC/DCBQ $(50 \%)$ is much lower than those of the other two hybrids. Furthermore, the utilization ratio of ZTC/DCBQ $(60 \%)$ is higher than that of mmAC/DCBQ (60\%), despite the lower surface area and pore volume of ZTC/DCBQ (60\%) compared to those of mmAC/DCBQ $(60 \%)$. The redox reaction of DCBQ requires not only the contact with the conductive carbon surface but also the proton conduction within the DCBQ-constrained pores because protons are involved in the redox reaction of DCBQ. Even if the surface areas of mmAC/DCBQ (60\%) and ZTC/DCBQ (60\%) are much lower than those of mmAC and ZTC, their pore structures are retained, as confirmed by the Raman spectroscopy results (Fig. 2); a large contact area between the DCBQ molecules and conductive carbon surfaces should be also retained. With these results, it can be concluded that mesopores with sizes less than $4 \mathrm{~nm}$ or 3D-ordered and mutually connected pores with a size of only $1.2 \mathrm{~nm}$ facilitate the proton conduction within the DCBQconstrained pores, thus increasing the utilization ratio of the adsorbed DCBQ. Although all the voltammograms are obtained at a relatively low sweep rate of $1 \mathrm{mV} \mathrm{s}^{-1}$, their charge/discharge 
characteristics exhibit marked differences at high charge/ discharge rates, which is discussed in the following section.

The effects of the pore sizes and the structures of porous carbons on the charge/discharge characteristics of the hybrids can be discussed by comparing the results of the GC analysis for each hybrid. Fig. $6 \mathrm{~d}-\mathrm{f}$ show the galvanostatic charge/discharge curves of $\mathrm{mAC} / \mathrm{DCBQ}(30 \%), \mathrm{mmAC} / \mathrm{DCBQ}(50 \%)$, and ZTC/ DCBQ $(60 \%)$, respectively, which exhibited the best electrochemical capacitor performance among the hybrids prepared from the corresponding porous carbons. The galvanostatic charge/discharge curves show a plateau at $c a .0 .4-0.6 \mathrm{~V}$, characteristic of the redox behavior of DCBQ, and exhibit a symmetrical profile in the low current density region $\left(<1 \mathrm{~A} \mathrm{~g}^{-1}\right)$. Meanwhile, the deviation from the symmetrical profile is observed in the high current density region $\left(>1 \mathrm{~A} \mathrm{~g}^{-1}\right)$. The volumetric capacitances of the $\mathrm{mAC} / \mathrm{DCBQ}$ hybrids are enhanced in the low current density region with the exception of $\mathrm{mAC} / \mathrm{DCBQ}(50 \%)$ and $\mathrm{mAC} / \mathrm{DCBQ}$ (55.1\%) (Fig. 6g). The electric double-layer formation within the pores of the porous carbons is disturbed by the adsorbed DCBQ molecules; consequently, DCBQ-derived pseudocapacitance is induced within the pores, i.e., the electric double-layer capacitance is substituted by the DCBQ-derived pseudocapacitance. The fact that the volumetric capacitance is enhanced by adsorbed DCBQ molecules suggests that the DCBQ-derived pseudocapacitance is superior to the electric double-layer capacitance in terms of volumetric capacitance enhancement because both capacitances are induced within the pores. The volumetric capacitance reaches the maximum for $\mathrm{mAC} / \mathrm{DCBQ}(30 \%)$ among all the $\mathrm{MAC} / \mathrm{DCBQ}$ hybrids, although it decreases with additional DCBQ content. This result suggests that the proton conduction is disturbed within DCBQ-constrained micropore spaces by additional DCBQ adsorption. The inferior rate capability (i.e., capacitance retention) of the $\mathrm{mAC} / \mathrm{DCBQ}$ hybrids is explained by the same reason. The capacitance retentions at $10 \mathrm{~A} \mathrm{~g}^{-1}$ in comparison with the capacitances at $50 \mathrm{~mA} \mathrm{~g}^{-1}$ are summarized in Table 4. The rate capabilities of all the $\mathrm{mAC} / \mathrm{DCBQ}$ hybrids are lower than that of $\mathrm{mAC}$; $\mathrm{mAC} / \mathrm{DCBQ}(50 \%)$ and $\mathrm{mAC} / \mathrm{DCBQ}$ (55.1\%) no longer exhibit volumetric capacitances over the whole current density region (Fig. $6 \mathrm{~g}$ ). On the other hand, the mmAC/DCBQ hybrids clearly exhibit higher volumetric

Table 4 Capacitance retentions at $10 \mathrm{~A} \mathrm{~g}^{-1}$ in comparison with the capacitance at $50 \mathrm{~mA} \mathrm{~g}^{-1}$

\begin{tabular}{lcll}
\hline DCBQ $(\mathrm{wt} \%)$ & mAC & mmAC & ZTC \\
\hline 0 & 31 & 38 & 48 \\
10 & & & 51 \\
20 & 11 & 59 & 73 \\
30 & 19 & & \\
40 & 14 & 56 & 72 \\
50 & 4 & 23 & 60 \\
60 & & $<1(<1)^{b}$ & $<1(<1)^{b}$ \\
Sat. $^{a}$ & 5 & &
\end{tabular}

${ }^{a}$ Saturation value: 55.1, 71.2, and $72.3 \mathrm{wt} \%$ for $\mathrm{mAC}$, $\mathrm{mmAC}$, and ZTC, respectively. ${ }^{b}$ The values in the parentheses are the results of the second measurement. capacitance enhancement than the mAC/DCBQ hybrids owing to DCBQ adsorption (Fig. 6h). Notably, the rate capabilities and volumetric capacitances of $\mathrm{mmAC} / \mathrm{DCBQ}(30 \%)$ and $\mathrm{mmAC} /$ DCBQ $(50 \%)$ are much higher than those of mmAC. Generally, for the electrodes of electric double-layer capacitors (EDLCs), mesopores facilitate ion diffusion within the pores and thus enhance rate capability, ${ }^{35,36}$ and a large surface area leads to a high capacitance. ${ }^{37,38}$ In contrast to the electric double-layer capacitance, it is also recognized that charge transfer reactions proceed relatively slowly in comparison with the electric double-layer formation. ${ }^{39,40}$ The superior rate capabilities of mmAC/DCBQ (30\%) and mmAC/DCBQ (50\%) compared with that of mmAC suggest that the redox reaction of DCBQ proceeds more rapidly than the electric double-layer formation even within the mesopores. ${ }^{14}$ Such a rapid charge transfer can be realized by fine dispersion of DCBQ and the resulting large contact area between the DCBQ molecules and conductive carbon surfaces, together with the mesopores of mmAC..$^{12,13,15}$ Conversely, a poor rate capability is observed for mmAC/DCBQ (60\%), whereas further volumetric capacitance enhancement is observed in the low current density region $\left(\sim 1000 \mathrm{~mA} \mathrm{~g}{ }^{-1}\right)$. Moreover, the volumetric capacitance of mmAC/DCBQ $(71.2 \%)$ is negligible over the whole current density region. This tendency implies that a certain pore volume is necessary to realize proton conduction within the DCBQconstrained mesopores.

Although both mAC and ZTC are microporous carbons, the ZTC/DCBQ hybrids show excellent rate capabilities up to a DCBQ content of $60 \%$ (Fig. 6i), irrespective of the small micropore size of ZTC (i.e., $1.2 \mathrm{~nm}$ ). The surface area of ZTC/ DCBQ $(60 \%)$ is merely $14 \mathrm{~m}^{2} \mathrm{~g}^{-1}$, which is lower than that of mmAC/DCBQ $(60 \%)\left(120 \mathrm{~m}^{2} \mathrm{~g}^{-1}\right)$. Nevertheless, ZTC/DCBQ $(60 \%)$ balances high volumetric capacitance and rate capability in comparison with the other samples. The compatibility of the excellent rate capability and high volumetric capacitance enhancement for ZTC/DCBQ (60\%) is realized by 3D-ordered and mutually connected pore structures, despite having a pore size of only $1.2 \mathrm{~nm}$. Such rapid proton conduction within the mostly filled but 3D-mutually connected micropores of ZTC/ DCBQ $(60 \%)$ can be explained by the Grotthuss mechanism and not the vehicle mechanism. ${ }^{41}$ In general, the ion conductivity of the proton is an order of magnitude higher than that of many other ions; ${ }^{42}$ however, discontinuous pores hinder the proton conduction based on both the Grotthuss and vehicle mechanisms. Accordingly, mmAC/DCBQ $(60 \%)$ shows a lower rate capability than that of ZTC/DCBQ $(60 \%)$ despite the little surface area of ZTC/DCBQ (60\%) because mmAC also has a discontinuous pore structure. Meanwhile, the pore structure of $\mathrm{mAC}$ is also discontinuous and $\mathrm{mAC}$ does not have mesopores; the proton conduction of the $\mathrm{mAC} / \mathrm{DCBQ}$ hybrids is further disturbed within the DCBQ-constrained micropores.

At this stage, it is still uncertain whether the electrolyte solution is impregnated into such constrained pore spaces of ZTC/DCBQ (60\%) or not. For the electrochemical measurement, electrodes were immersed into the electrolyte solution under vacuum for $10 \mathrm{~min}$ and left for more three days at $40{ }^{\circ} \mathrm{C}$ to exclude the effect of the inadequacy of electrolyte impregnation 
on the electrochemical capacitor performance. Afterward, we examined the effect of the degree of electrolyte impregnation on their electrochemical performance by changing the impregnation condition. As an additional experiment, we analyzed ZTC/ DCBQ $(60 \%)$ by CV immediately after the immersion of the electrode into the electrolyte solution, i.e., without vacuuming and the impregnation at $40{ }^{\circ} \mathrm{C}$ (Fig. S7 $\dagger$ ). During the 1 st cycle, the current in the voltammogram was lower than that of the ZTC/DCBQ $(60 \%)$ fully impregnated with the electrolyte (Fig. S2c $\dagger$ ). However, unexpectedly, the current quickly increased and reached the same value at the 4 th cycle as that of the fully impregnated ZTC/DCBQ (60\%). The electrolyte impregnation may be accelerated by the electric field during the $\mathrm{CV}$ measurement, but this result confirmed the impregnation of the electrolyte solution even for ZTC/DCBQ (60\%). In addition, the impregnated electrolyte solution, of which amount must be negligible considering the remaining pore volume of ZTC/ DCBQ $(60 \%)$, plays an important role in the rapid redox reaction of DCBQ and the proton conduction within the mostly filled micropores.

Since ZTC/DCBQ (72.3\%) and mmAC/DCBQ (71.2\%) have little surface area (Table 1), their capacitances are much lower than those of the other ZTC/DCBQ and mmAC/DCBQ hybrids (Fig. 6h and i). However, in the low current density region, ZTC/ DCBQ $(72.3 \%)$ shows certain capacitances. After their electrochemical measurement, both cells were kept at $25{ }^{\circ} \mathrm{C}$ for a week and then measured again to examine the change in electrolyte impregnation. Consequently, the capacitances of ZTC/DCBQ $(72.3 \%)$ at current densities less than $1 \mathrm{~A} \mathrm{~g}^{-1}$ were markedly enhanced, while the capacitances of mmAC/DCBQ $(71.2 \%)$ did not increase. This result evidenced that the remaining pores less than a $\mathrm{N}_{2}$ molecule exist in ZTC/DCBQ (72.3\%), and 3Dordered and mutually connected pores accelerate the impregnation of the electrolyte solution even in the saturated micropores, whereas the proton conduction is hampered by saturating DCBQ molecules at high charge/discharge rates.

Lastly, we examined the cycle lifetimes of mmAC/DCBQ (50\%), which can be prepared from conventional AC with micro- and mesopores and balanced high volumetric capacitances with excellent rate capabilities. The cycle test was performed by GC measurement at a current density of $1 \mathrm{~A} \mathrm{~g}^{-1}$ with a cell voltage from 0 to $0.8 \mathrm{~V}$ using a symmetrical two-electrode cell. Note that a current density of $1 \mathrm{~A} \mathrm{~g}^{-1}$ for a two-electrode cell corresponds to one of $2 \mathrm{~A} \mathrm{~g}^{-1}$ for a three-electrode cell. As shown in Fig. 7a, mmAC/DCBQ (50\%) well retains a capacitance over the cycles, and the color of the electrolyte solution did not change throughout the measurements, indicating the absence of the desorption or decomposition of the adsorbed DCBQ. Excellent cycle lifetimes of $84 \%$ with a high coulombic efficiency above 99\% were achieved for mmAC/DCBQ (50\%) after the 10 000th cycle (Fig. 7b). The reason for the long cycle lifetimes is attributed to the electroneutrality of DCBQ by protonation upon the reduction of DCBQ. If DCBQ did not undergo the protonation, DCBQ would be negatively charged after the reduction, and therefore, be pulled to the oppositely (i.e., positively) charged counter electrode, resulting in the desorption into the electrolyte solution (Fig. 7, inset). ${ }^{\mathbf{4 3}}$ Moreover, the two


Fig. 7 Capacitance dependence of $\mathrm{mmAC} / \mathrm{DCBQ}(50 \%)$ on the cycle number measured using a symmetrical two-electrode cell at a current density of $1 \mathrm{~A} \mathrm{~g}^{-1}$ with a cell voltage from 0 to $0.8 \mathrm{~V}$. (a) Gravimetric and volumetric capacitance dependences on the cycle number. (b) Dependences of capacitance retention and coulombic efficiency on the cycle number.

hydrophilic chlorine atoms in a DCBQ molecule are effective to suppress the desorption of DCBQ. These two factors are essential for the long cycle lifetimes of porous carbon/DCBQ hybrids as electrochemical capacitor electrodes.

The results obtained in this study offer insights into the further enhancement of the volumetric capacitance and power density while retaining long cycle lifetimes of electrochemical capacitor electrodes, using quinone derivatives and appropriate porous carbons. Mesopores or 3D-ordered and mutually connected pores are effective for enhancing the volumetric capacitance and rate capability, and the fine dispersion of DCBQ inside the pores of porous carbons enables a large contact area between the conductive carbon surface and DCBQ molecules. The densities of the porous carbons with abundant mesopore volumes are lower than those of microporous carbons, and such porous carbons have lower volumetric capacitances than microporous carbons as EDLC electrodes. ${ }^{23}$ However, the amount of the adsorbed DCBQ proportionally increases with the total pore volumes, and the volumetric capacitances obtained in this study by DCBQ adsorption reached 2.5 times higher than those of the pristine porous carbons, which compensates for the low density of mesoporous carbons. There 
are many porous carbon candidates, such as hierarchical porous carbons and ordered mesoporous carbons, ${ }^{36,44}$ which can adsorb a large amount of DCBQ. They can, therefore, serve as DCBQ host materials for obtaining high volumetric capacitances. In particular, the pore structures of ordered mesoporous carbons are expected to balance high volumetric capacitances with high power densities by DCBQ-derived pseudocapacitance, significantly better than those of ZTC/DCBQ hybrids.

\section{Conclusions}

We demonstrated the synthesis, analysis, and electrochemical measurement of the porous carbon/quinone derivative hybrids using three kinds of porous carbons with different pore sizes and structures. This method is not accompanied by the volumetric expansion of the electrodes in comparison with those prepared from pristine porous carbons, and the adsorbed DCBQ undergoes rapid redox reactions within the pores, thus enhancing the volumetric capacitance. The volumetric capacitance enhancement of the porous carbon/DCBQ hybrids exhibited different electrochemical behaviors, depending on the kind of pore sizes and structures of the porous carbons. We revealed that the proton conduction was disturbed within the DCBQ-constrained micropores; however, it was facilitated in mesopores. In addition, 3D-ordered and mutually connected micropores with a size of only $1.2 \mathrm{~nm}$ were found to be superior to the mesopores of AC with sizes less than $4 \mathrm{~nm}$, in terms of balancing the high volumetric capacitance enhancement with the high rate capability through the DCBQ-derived pseudocapacitance. However, all the porous carbons saturated with DCBQ had a detrimental effect on the compatibility between the volumetric capacitance enhancement and rate capability. The observed behavior of the proton conduction within the DCBQconstrained carbon pores can be explained only by the Grotthuss mechanism. This hybridization method is free from organic solvents and solvent removal, and hydrophobic DCBQ is useful for enhancing both the volumetric capacitance and rate capability of aqueous electrochemical capacitors. These experimental results provided new insights into porous carbon/ quinone derivative hybrids as aqueous electrochemical capacitor electrodes involving proton conduction. Our method will facilitate the production of aqueous electrochemical capacitors superior to those reported thus far, via the combination of many other quinone derivatives and porous carbons with appropriate pore structures and sizes.

\section{Conflicts of interest}

There are no conflicts to declare.

\section{Acknowledgements}

This work was supported by JSPS KAKENHI Grant Number 15K21478 and 17K06034.

\section{Notes and references}

1 H. W. Kroto, J. R. Heath, S. C. O'Brien, R. F. Curl and R. E. Smalley, Nature, 1985, 318, 162-163.

2 S. Iijima, Nature, 1991, 354, 56-58.

3 S. Iijima and T. Ichihashi, Nature, 1993, 363, 603-605.

4 K. S. Novoselov, A. K. Geim, S. V. Morozov, D. Jiang, Y. Zhang, S. V. Dubonos, I. V. Grigorieva and A. A. Firsov, Science, 2004, 306, 666-669.

5 E. Hernández, V. Meunier, B. W. Smith, R. Rurali, H. Terrones, M. Buongiorno Nardelli, M. Terrones, D. E. Luzzi and J. C. Charlier, Nano Lett., 2003, 3, 1037-1042.

6 M. Endo, T. Hayashi, H. Muramatsu, Y.-A. Kim, H. Terrones, M. Terrones and M. S. Dresselhaus, Nano Lett., 2004, 4, 14511454.

7 Y. Feng, L. Zhou, Q. Wan, S. Lin and H. Guo, Chem. Sci., 2018, 9, 5890-5896.

8 Y. Zheng, Y. Jiao, J. Chen, J. Liu, J. Liang, A. Du, W. Zhang, Z. Zhu, S. C. Smith, M. Jaroniec, G. Q. Lu and S. Z. Qiao, J. Am. Chem. Soc., 2011, 133, 20116-20119.

9 M. E. Casco, J. Silvestre-Albero, A. J. Ramírez-Cuesta, F. Rey, J. L. Jordá, A. Bansode, A. Urakawa, I. Peral, M. MartínezEscandell, K. Kaneko and F. Rodríguez-Reinoso, Nat. Commun., 2015, 6, 6432.

10 K. Urita, Y. Shiga, T. Fujimori, T. Iiyama, Y. Hattori, H. Kanoh, T. Ohba, H. Tanaka, M. Yudasaka, S. Iijima, I. Moriguchi, F. Okino, M. Endo and K. Kaneko, J. Am. Chem. Soc., 2011, 133, 10344-10347.

11 T. Fujimori, A. Morelos-Gómez, Z. Zhu, H. Muramatsu, R. Futamura, K. Urita, M. Terrones, T. Hayashi, M. Endo, S. Young Hong, Y. Chul Choi, D. Tománek and K. Kaneko, Nat. Commun., 2013, 4, 2162.

12 H. Itoi, S. Hayashi, H. Matsufusa and Y. Ohzawa, Chem. Commun., 2017, 53, 3201-3204.

13 H. Itoi, S. Maki, T. Ninomiya, H. Hasegawa, H. Matsufusa, S. Hayashi, H. Iwata and Y. Ohzawa, Nanoscale, 2018, 10, 9760-9772.

14 H. Itoi, Y. Yasue, K. Suda, S. Katoh, H. Hasegawa, S. Hayashi, M. Mitsuoka, H. Iwata and Y. Ohzawa, ACS Sustainable Chem. Eng., 2017, 5, 556-562.

15 H. Itoi, H. Hasegawa, H. Iwata and Y. Ohzawa, Sustainable Energy Fuels, 2018, 2, 558-565.

16 Y. F. Li, R. Hatakeyama, T. Kaneko, T. Izumida, T. Okada and T. Kato, Nanotechnology, 2006, 17, 4143-4147.

17 T. Takenobu, T. Takano, M. Shiraishi, Y. Murakami, M. Ata, H. Kataura, Y. Achiba and Y. Iwasa, Nat. Mater., 2003, 2, 683688.

18 Y.-E. Miao, W. Fan, D. Chen and T. Liu, ACS Appl. Mater. Interfaces, 2013, 5, 4423-4428.

19 L. B. J. da Silva and R. L. Oréfice, J. Polym. Res., 2014, 21, 1-9. 20 C. J. T. De Grotthuss, Ann. Chim., 1806, 58, 54-74.

21 N. Agmon, Chem. Phys. Lett., 1995, 244, 456-462.

22 K.-D. Kreuer, A. Rabenau and W. Weppner, Angew. Chem., Int. Ed. Engl., 1982, 21, 208-209.

23 H. Itoi, H. Nishihara, T. Kogure and T. Kyotani, J. Am. Chem. Soc., 2011, 133, 1165-1167. 
24 H. Itoi, H. Nishihara and T. Kyotani, Langmuir, 2016, 32, 11997-12004.

25 K. Kaneko and C. Ishii, Colloids Surf., 1992, 67, 203-212.

26 H. Nishihara, H. Fujimoto, H. Itoi, K. Nomura, H. Tanaka, M. T. Miyahara, P. A. Bonnaud, R. Miura, A. Suzuki, N. Miyamoto, N. Hatakeyama, A. Miyamoto, K. Ikeda, T. Otomo and T. Kyotani, Carbon, 2018, 129, 854-862.

27 Z. X. Ma, T. Kyotani, Z. Liu, O. Terasaki and A. Tomita, Chem. Mater., 2001, 13, 4413-4415.

28 M. Ito, H. Nishihara, K. Yamamoto, H. Itoi, H. Tanaka, A. Maki, M. T. Miyahara, S. J. Yang, C. R. Park and T. Kyotani, Chem.-Eur. J., 2013, 19, 13009-13016.

29 V. Y. Yakovlev, A. A. Fomkin and A. V. Tvardovski, J. Colloid Interface Sci., 2003, 268, 33-36.

30 A. A. Fomkin, Adsorption, 2005, 11, 425-436.

31 P. I. Ravikovitch and A. V. Neimark, Langmuir, 2006, 22, 10864-10868.

32 E. A. Ustinov and D. D. Do, Carbon, 2006, 44, 2652-2663.

33 P. Kowalczyk, A. Ciach and A. V. Neimark, Langmuir, 2008, 24, 6603-6608.

34 H. Itoi, H. Nishihara, T. Ishii, K. Nueangnoraj, R. BerenguerBetrián and T. Kyotani, Bull. Chem. Soc. Jpn., 2014, 87, 250257.
35 K. Jurewicz, C. Vix-Guterl, E. Frackowiak, S. Saadallah, A. Reda, J. Parmentier, J. Patarin and F. Beguin, J. Phys. Chem. Solids, 2004, 65, 287-293.

36 W. Xing, S. Z. Qiao, R. G. Ding, F. Li, G. Q. Lu, Z. F. Yan and H. M. Cheng, Carbon, 2006, 44, 216-224.

37 G. Lota, T. A. Centeno, E. Frackowiak and F. Stoeckli, Electrochim. Acta, 2008, 53, 2210-2216.

38 M. Sevilla, S. Alvarez, T. A. Centeno, A. B. Fuertes and F. Stoeckli, Electrochim. Acta, 2007, 52, 3207-3215.

39 E. Frackowiak and F. Beguin, Carbon, 2001, 39, 937-950.

40 Z. Song and H. Zhou, Energy Environ. Sci., 2013, 6, 22802301.

41 M. von der Lehr, C. F. Seidler, D. H. Taffa, M. Wark, B. M. Smarsly and R. Marschall, ACS Appl. Mater. Interfaces, 2016, 8, 25476-25488.

42 D. A. MacInnes, The Principles of Electrochemistry, Dover, 1961.

43 H. Itoi, K. Shimomura, H. Hasegawa, N. Nomura, Y. Ohta, H. Iwata, Y. Hoshikawa and Y. Ohzawa, Adv. Mater. Interfaces, 2019, 6, 1801799.

44 H. Yamada, H. Nakamura, F. Nakahara, I. Moriguchi and T. Kudo, J. Phys. Chem. C, 2007, 111, 227-233. 